\title{
Estimation of the Trichomonad Concentration in Beef Bull Preputial Samples and Resultant Population Effect of Pooling on Detection of Tritrichomonas foetus Using qPCR
}

\author{
David J Wilson*, Thomas J Baldwin, Amanda Wilhelm, Chelsea H Whitehouse, Jennifer L Bunnell, Kerry A Rood and Arnaud Van Wettere J
}

School of Veterinary Medicine, Department of Animal, Dairy and Veterinary Sciences, Utah State University, 950 East 1400 North, Logan, UT 84341, USA

"Corresponding author: David JW, School of Veterinary Medicine, Department of Animal, Dairy and Veterinary Sciences, Utah State University, 950 East 1400 North, Logan, UT 84341, USA, Tel: (435) 760-3731; Fax: (435) 797-2805; E-mail: David.Wilson@usu.edu

Rec date: March 20, 2017; Acc date: March 28, 2017; Pub date: March 30, 2017

Copyright: ( 2017 Wilson DJ, et al. This is an open-access article distributed under the terms of the Creative Commons Attribution License, which permits unrestricted use, distribution, and reproduction in any medium, provided the original author and source are credited.

\begin{abstract}
The primary objective was assessment of effect of sample pooling on Tritrichomonas foetus detection using qPCR in beef bulls within 5 logs of trichomonad concentration in spiked preputial samples. The secondary objective was to use qPCR Ct values to estimate the percentage of beef bulls in the field population within each log of trichomonad concentration. Solutions containing none, 1,10,100,1000 and 10,000 trichomonads $(\mathrm{T}) / \mathrm{ml}$ were made and tested by qPCR. Test sensitivities for single positive samples were: $1 \mathrm{~T} / \mathrm{ml}, 20 / 40$ (50\%); 10 T/ml, 40/40 (100\%); $100 \mathrm{~T} / \mathrm{ml}, 40 / 40$ (100\%); $1000 \mathrm{~T} / \mathrm{ml}, 40 / 40$ (100\%); 10,000 T/ml, $40 / 40(100 \%)$. For 5-sample pools (1 positive and 4 negative), sensitivities were: $1 \mathrm{~T} / \mathrm{ml}, 6 / 40$ (15\%), $10 \mathrm{~T} / \mathrm{ml}, 26 / 40$ (65\%); $100 \mathrm{~T} / \mathrm{ml} 40 / 40$ (100\%); $1000 \mathrm{~T} / \mathrm{ml}, 40 / 40$ $(100 \%) ; 10,000 \mathrm{~T} / \mathrm{ml}, 40 / 40(100 \%)$. Specificity for both single and pooled negative samples was $40 / 40$ negative $(100 \%)$. Diagnostic field samples $(n=130)$ in which $T$. foetus was detected by qPCR were classified by Ct to estimate the proportion of positive bulls within each trichomonad concentration: $1 \mathrm{~T} / \mathrm{ml} 10(7.7 \%) ; 10 \mathrm{~T} / \mathrm{ml} 17(13.1 \%) ; \geq 100$ $\mathrm{T} / \mathrm{ml} 103(79.2 \%)$. Accounting for the above sensitivities and proportions of bulls, sensitivity for trichomoniasis detection in the bull population was $96.2 \%$ using single preputial samples and $88.9 \%$ using 5 -sample pools. Therefore $7.3 \%$ of all $T$. foetus-positive bulls were not detected using 5 -sample pools compared with using single samples. Detection of bovine trichomoniasis by qPCR is minimally affected by using 5-sample pools, considering the trichomonad concentration of most positive bulls.
\end{abstract}

Keywords: Trichomoniasis; Bovine; Bulls; Individual samples; Pooled samples

\section{Introduction}

Bovine trichomoniasis is a venereal disease of cattle caused by the protozoan Tritrichomonas foetus. Infection with $T$. foetus results in decreased pregnancy rates and increased cases of abortion, stillbirth, endometritis and pyometra. In bulls, infection is subclinical [1-3]. Interestingly, no refereed publications regarding financial loss have been authored in the past 25 years; virtually all references to the cost of bovine trichomoniasis cite Rae in 1989 [4] who stated that productivity and profitability of cow-calf operations were reduced by $5 \%$ to $35 \%$ as measured by return per cow attempted to be impregnated. To date, the most effective control strategies for bovine trichomoniasis focus on identification and elimination of infected carrier bulls [2,3].

Most states have trichomoniasis control programs that focus on testing of bulls and elimination of positive animals. As a result of such a program, prevalence of trichomoniasis in bulls in the state of Utah has declined from national historic levels of approximately 5\% [5] to $0.06 \%$ in 2016 (Unpublished data, Utah Veterinary Diagnostic Laboratory [UVDL], 2016). Identification of carrier bulls is accomplished by collection of preputial scraping samples followed by either: 1) protozoal culture and microscopic identification, 2) protozoal culture followed by polymerase chain reaction (PCR)-based identification, or 3) PCR-based identification alone [3,6-8]. Although protozoal culture has been historically considered the gold-standard method of detection, the reported sensitivity of culture for identification of $T$. foetus varies $(67.8 \%$ to $98.4 \%)$, depending on factors such as sample collection, transport, and specific culture methods employed [7-9].

The development of PCR for detection of $T$. foetus has resulted in a lower limit of detection, the ability to detect lower concentrations of trichomonads $(\mathrm{T}) / \mathrm{ml}$ in preputial samples, and increased sensitivity compared to culture methods $[3,6,10]$. However, PCR assays are more expensive. Because PCR testing is more sensitive, pooled testing of preputial samples is of interest to beef producers and veterinarians as a means to reduce costs.

The use of pooled samples from multiple bulls for trichomoniasis detection has been evaluated previously [11]. Preputial scrapings from 187 virgin bulls and 150 steers in Canada, defined as true negatives, were evaluated for false-positive results for $T$. foetus using both culture and qPCR. Specificity was $98.8 \%$ (333/337 correctly tested negative) for culture and $100 \%$ (no false positives) for qPCR. The same study evaluated sensitivity of $\mathrm{qPCR}$ on pooled samples, using negative preputial scrapings spiked with $T$. foetus obtained from a test-positive (naturally infected) bull. Samples were formulated with trichomonads $(\mathrm{T}) / \mathrm{ml}$ of $1000,10,000,100,000$ and 1,000,000. From each $\mathrm{T}$ concentration, pools were created with one T. foetus-positive sample in pools of $2,3,5,10,20$ and 25 total samples. Sensitivities for detection of trichomonads (detecting the presence of the one positive bull) for the sample pool ratios were: $1: 10,90.3 \% ; 1: 2,1: 15,1: 20$, and 1:25, 93.5\%; and 1:3 and 1:5, 96.8\%. Overall sensitivity of the qPCR for detection of $T$. foetus was $94 \%$. Differences in sensitivity among the different sizes of sample pools were not significant $(\mathrm{P}=0.70)$ [11]. 
Citation: Wilson DJ, Thomas JB, Amanda W, Chelsea HW, Jennifer LB, et al. (2017) Estimation of the Trichomonad Concentration in Beef Bull Preputial Samples and Resultant Population Effect of Pooling on Detection of Tritrichomonas foetus Using qPCR. J Vet Sci Technol 8: 434. doi:10.4172/2157-7579.1000434

Page 2 of 3

Preputial samples from 305 non-virgin bulls were used in a Colorado study [12]. Solutions of 3,000, 300, 30, 3 and $0.3 \mathrm{~T} / \mathrm{ml}$ were made from PCR T. foetus-positive bulls. The "individual bull sample" solutions of $3,000,300$, and $30 \mathrm{~T} / \mathrm{ml}$ were $100 \%$ classified as detected (each concentration had 14/14 samples positive) by PCR. The 3 and 0.3 $\mathrm{T} / \mathrm{ml}$ solutions were $86 \%(12 / 14)$ and $50 \%(7 / 14)$ detected as positive by PCR. The 305 original preputial samples were used to create 61 pooled samples with 5 different bulls in each pool, with 16 pools having one positive bull with 4 negative bulls, and 45 pools having 5 negative bulls. The composition of the pools was blinded to the technicians doing PCR testing. The concentration of $\mathrm{T} / \mathrm{ml}$ in the original samples used to make the pools was not determined. Sensitivity of the PCR on 5-sample pools was $100 \%$ (16/16). Specificity was also $100 \%$, but this value was calculated using culture as the "gold standard", which resulted in 2 sample pools being detected as positive for $T$. foetus that were culture-negative, resulting in an alternative calculation of specificity as $95.7 \%(45 / 47)$ [12].

The main objective of the study reported here was to determine the sensitivity (\% of true positives detected as positives) and specificity (\% of true negatives tested as negatives) of a qPCR for the detection of $T$. foetus in single spiked samples and compare to those same test characteristics for 5 -sample pools ( 1 positive and 4 negative). Five logs of trichomonad concentration $(\mathrm{T} / \mathrm{ml})$ were tested. A secondary objective was to use qPCR Ct values from the spiked samples to estimate the proportion of $T$. foetus-positive bulls that naturally occur within each $\log$ of $\mathrm{T} / \mathrm{ml}$ concentration, based on the positive bulls' $\mathrm{Ct}$ values.

\section{Materials and Methods}

\section{Spiked single and pooled sample preparation}

Live T. foetus (Biomed Diagnostics Inc., White City, OR) and InPouch (IP) (TF Media, Biomed Diagnostics Inc., White City, OR) culture media were purchased and $60 \mathrm{ml}$ of a stock solution of 10,000 trichomonads $(\mathrm{T}) / \mathrm{ml}$ in culture IP media was made. The trichomonad concentration was estimated using a hemocytometer. Using this 10,000 $\mathrm{T} / \mathrm{ml}$ stock solution, $60 \mathrm{ml}$ of $10,000,1000,100,10$ and $1 \mathrm{~T} / \mathrm{ml}$ solutions were made using 10-fold serial dilutions. In-Pouch culture media was used as a T. foetus-negative solution. Forty samples of each of the following were prepared and tested by qPCR: negative single samples and negative 5-sample pools, $1 \mathrm{~T} / \mathrm{ml}$ single samples and 5sample pools (all pools consisted of 1 positive and 4 negative), $10 \mathrm{~T} / \mathrm{ml}$ single samples and 5-sample pools, $100 \mathrm{~T} / \mathrm{ml}$ single samples and 5sample pools, $1000 \mathrm{~T} / \mathrm{ml}$ single samples and 5-sample pools, and $10,000 \mathrm{~T} / \mathrm{ml}$ single samples and 5 -sample pools. Each pool of 5 samples was prepared by pipetting $1000 \mu \mathrm{l}$ from the negative solution or $200 \mu \mathrm{l}$ from the $1,10,100,1000$, or $10,000 \mathrm{~T} / \mathrm{ml}$ solution was added to $800 \mu$ of the negative solution to create a pooled sample volume of 1 $\mathrm{ml}$.

\section{Trichomonad concentrations in naturally infected bulls' preputial samples}

The spiked $1 \mathrm{ml}$ samples of the 5 concentrations of $\mathrm{T} / \mathrm{ml}$ described above were used to determine the ranges of $\mathrm{qPCR}$ Ct values for samples within each log of trichomonad concentration. Diagnostic preputial samples in culture IP media pouches or tubes were incubated for $24 \mathrm{~h}$ at $37^{\circ} \mathrm{C}$ following collection by field veterinarians, then frozen and sent to the UVDL for qPCR testing. The Ct values of all bulls naturally infected with $T$. foetus and classified as positive or suspect at the UVDL from 2010 to 2016 were used to assign them to a $\log$ of $\mathrm{T} / \mathrm{ml}$ concentration.

\section{DNA extraction and qPCR}

DNA was extracted and purified from one $\mathrm{ml}$ of single or pooled samples using a commercial extraction kit (NucleoMag 96 Genomic DNA from Tissue Kit, Macherey-Nagel, Inc. Bethlehem, PA) according to the manufacturer's instructions. The primers, probe, and reaction conditions were the same as described by McMillen and Lew, 2006 [10]. The reactions were run for 38 cycles on an Applied Biosystems 7500 Fast Real-Time PCR System. For diagnostic samples, samples with a $\mathrm{Ct}<38$ were classified as positive. Samples with a $\mathrm{Ct}>38$ were classified as negative.

\section{Statistical analysis}

Trichomonad concentration group and whether samples were single samples or 5-sample pools were both categorical variables. Whether trichomoniasis was detected (positive) or not detected (negative) was also a categorical variable. Statistically significant differences in detection of $T$. foetus between concentrations within the single or pooled sample categories, and between single or pooled samples within each $\mathrm{T} / \mathrm{ml}$ concentration category were tested using Chi-square. The level of significance was $\alpha=0.05$.

\section{Results}

Results are summarized in Table 1 . The $50 \%$ sensitivity of qPCR testing single samples with $1 \mathrm{~T} / \mathrm{ml}$ for $T$. foetus was significantly lower than the $100 \%$ sensitivity for single samples within all higher trichomonad concentrations $(\mathrm{P}<0.0001)$. For samples with $1 \mathrm{~T} / \mathrm{ml}$, the $15 \%$ sensitivity when testing 5 -sample pools ( 1 positive and 4 negative) was significantly lower than the $50 \%$ sensitivity when testing single samples $(\mathrm{P}=0.01)$. For samples with $10 \mathrm{~T} / \mathrm{ml}$, the $65 \%$ sensitivity when testing 5-sample pools was significantly lower than the $100 \%$ sensitivity when testing single samples $(\mathrm{P}<0.001)$.

\begin{tabular}{|l|l|l|}
\hline Trichomonads/ml & Single or Pooled Samples & Sensitivity \\
\hline 1 & Single & $20 / 40(50 \%)^{\mathrm{a}}$ \\
\hline 1 & 5 -sample pool & $6 / 40(15 \%)^{\mathrm{b}}$ \\
\hline 10 & Single & $40 / 40(100 \%)^{\mathrm{c}}$ \\
\hline 10 & 5 -sample pool & $26 / 40(65 \%)^{\mathrm{d}}$ \\
\hline 100 & Single & $40 / 40(100 \%)^{\mathrm{c}}$ \\
\hline 100 & 5-sample pool & $40 / 40(100 \%)^{\mathrm{e}}$ \\
\hline 1000 & Single & $40 / 40(100 \%)^{\mathrm{c}}$ \\
\hline 1000 & 5-sample pool & $40 / 40(100 \%)^{\mathrm{e}}$ \\
\hline 10,000 & Single & $40 / 40(100 \%)^{\mathrm{c}}$ \\
\hline 10,000 & 5-sample pool & $40 / 40(100 \%)^{\mathrm{e}}$ \\
\hline
\end{tabular}

Table 1: Sensitivity of qPCR for detection of Tritrichomonas fetus in single spiked samples or 5 -sample pools ( 1 positive and 4 negative) by trichomonad concentration. a,b Significantly lower sensitivity for 5sample pools ( 1 positive and 4 negative) than for single samples with 1 
Citation: Wilson DJ, Thomas JB, Amanda W, Chelsea HW, Jennifer LB, et al. (2017) Estimation of the Trichomonad Concentration in Beef Bull Preputial Samples and Resultant Population Effect of Pooling on Detection of Tritrichomonas foetus Using qPCR. J Vet Sci Technol 8: 434. doi:10.4172/2157-7579.1000434

Page 3 of 3

trichomonad $(\mathrm{T}) / \mathrm{ml}, \mathrm{P}=0.01$. $^{\mathrm{a}, \mathrm{c}}$ Significantly lower sensitivity for single samples with $1 \mathrm{~T} / \mathrm{ml}$ than for single samples with higher trichomonad concentrations, $\mathrm{P}<0.0001$. $^{\mathrm{c}, \mathrm{d}}$ Significantly lower sensitivity for 5 -sample pools than for single samples with $10 \mathrm{~T} / \mathrm{ml}, \mathrm{P}<0.001$. $^{\text {b,d,e }}$ Significantly lower sensitivity for 5 -sample pools with $1 \mathrm{~T} / \mathrm{ml}$ or $10 \mathrm{~T} / \mathrm{ml}$ than pooled samples with higher trichomonad concentrations, $\mathrm{P}<0.0001$. All other sensitivity values of $100 \%$ were not different.

Considering only 5 -sample pools, the $15 \%$ sensitivity for $1 \mathrm{~T} / \mathrm{ml}$ $(\mathrm{P}<0.0001)$ and the $65 \%$ sensitivity for $10 \mathrm{~T} / \mathrm{ml} \quad(\mathrm{P}<0.0001)$ were significantly lower than the $100 \%$ sensitivity for pooled samples within all higher trichomonad concentrations. Specificity of qPCR when tested on single $(n=40)$ or 5 -sample pooled $(n=40)$ negative samples was $100 \%$ (all test results were "not detected").

The Ct values of the 130 naturally infected T. foetus-positive bulls detected at UVDL from 2010 - 2016 were used to classify each bull within a $\log$ of $\mathrm{T} / \mathrm{ml}$, based on the ranges of $\mathrm{Ct}$ values within each $\log$ of the spiked samples. The $\mathrm{Ct}$ ranges that defined each trichomonad concentration were: $1 \mathrm{~T} / \mathrm{ml}$, Ct 35.0 to $37.99 ; 10 \mathrm{~T} / \mathrm{ml}$, Ct 32.0 to 34.99 ; $100 \mathrm{~T} / \mathrm{ml}$, Ct 28.5 to $31.99 ; 1000 \mathrm{~T} / \mathrm{ml}$, Ct 25.5 to $28.49 ; 10,000 \mathrm{~T} / \mathrm{ml}$, $\mathrm{Ct}<25.5$. Based on these criteria, the proportions of all bulls within the logs of T/ml were: $1 \mathrm{~T} / \mathrm{ml}, 10$ bulls (7.7\%); $10 \mathrm{~T} / \mathrm{ml}, 17$ bulls (13.1\%); $\geq$ $100 \mathrm{~T} / \mathrm{ml}, 103$ bulls (79.2\%). The latter group of 103 bulls, all of which had $100 \%$ test sensitivity by either method, consisted of: $100 \mathrm{~T} / \mathrm{ml}, 27$ bulls (20.7\%); $1000 \mathrm{~T} / \mathrm{ml}, 36$ bulls (27.7\%); 10,000 T/ml, 40 bulls (30.8\%). The overall population sensitivity for qPCR detection of $T$. foetus in preputial scrapings from bulls was calculated, accounting for the proportions of bulls within trichomonad concentrations above. For single samples: $7.7 \%$ of positive bulls $(1 \mathrm{~T} / \mathrm{ml}) \times 50 \%$ sensitivity $(0.5 \times$ $7.7 \%)=3.9 \%$ detected. All of the $92.3 \%$ remaining positive bulls $(\geq 10$ $\mathrm{T} / \mathrm{ml}$ ) were detected (100\% sensitivity). Therefore the proportion of all positive bulls detected, the sensitivity of single sample qPCR testing $=3.9 \%+92.3 \%=96.2 \%$. For 5 -sample pools ( 1 positive and 4 negative): $7.7 \%$ of positive bulls $(1 \mathrm{~T} / \mathrm{ml}) \times 15 \%$ sensitivity $(0.15 \times$ $7.7 \%)=1.2 \%$ detected; $13.1 \%$ of positive bulls $(10 \mathrm{~T} / \mathrm{ml}) \times 65 \%$ sensitivity $(0.65 \times 13.1 \%)=8.5 \%$ detected; all of the $79.2 \%$ remaining positive bulls $(\geq 100 \mathrm{~T} / \mathrm{ml})$ were detected. Therefore the proportion of all positive bulls detected, the sensitivity of 5-sample pool qPCR testing $=1.2 \%+8.5 \%+79.2 \%=88.9 \%$. The proportion of all $T$. foetus positive bulls not detected when using 5 -sample pools compared with that using single samples $=(96.2 \%-88.9 \%)=7.3 \%$.

\section{Discussion}

There was some loss of overall sensitivity of qPCR for detection of $T$. foetus infected bulls when 5-sample pools were tested compared with single samples. The greatest loss of sensitivity associated with pooling (or when testing single samples, but less so) was for bulls with $1 \mathrm{~T} / \mathrm{ml}$. However, because these low trichomonad concentration bulls represented less than $8 \%$ of the total population, the overall sensitivity of qPCR for detection of trichomoniasis was high using either pooled (89\%) or single (96\%) samples.

Beef producers and veterinarians wishing to minimize the probability of failing to detect any bull infected with $T$. foetus should continue to test bulls using individual preputial scraping samples. If a group of bulls were tested that contained a higher proportion of bulls with $1 \mathrm{~T} / \mathrm{ml}$ or $10 \mathrm{~T} / \mathrm{ml}$ than the population mean, the loss of sensitivity with pooling would also increase. However, there is reasonable evidence for testing bulls for trichomoniasis with $\mathrm{qPCR}$ using pooled samples from 5 bulls.

\section{Acknowledgements}

Financial support for this study was from the Utah Department of Agriculture and Food, and the Summer Research Internship program of the School of Veterinary Medicine, Utah State University. We thank John Hergert for help with initial preparation of the spiked trichomonad samples.

\section{References}

1. Baltzell P, Newton H, O'Connor AM (2013) A critical review and metaanalysis of the efficacy of whole-cell killed Tritrichomonas foetus vaccines in beef cattle. J Vet Intern Med. 27: 760-770.

2. Corbeil LB (1994) Vaccination strategies against Tritrichomonas foetus. Parasitol Today. 10: 103-106.

3. Parker S, Lun ZR, Gajadhar A (2001) Application of a PCR assay to enhance the detection and identification of Tritrichomonas foetus in cultured preputial samples. J Vet Diagn Invest. 13: 508-513.

4. Rae DO (1989) Impact of trichomoniasis on the cow-calf producer's profitability. J Am Vet Med Assoc. 194: 771-775.

5. BonDurant RH, Anderson ML, Blanchard P, Hird D, Danaye-Elmi C, et al. (1990) Prevalence of trichomoniasis among California beef herds. J Am Vet Med Assoc. 196: 1590-1593.

6. Campero CM, Rodriguez Dubra C, Bolondi A, Cacciato C, Cobo E, et al. (2003) Two-step (culture and PCR) diagnostic approach for differentiation of non- $T$ foetus trichomonads from genitalia of virgin beef bulls in Argentina. Vet Parasitol. 112: 167-175.

7. Cobo ER, Favetto PH, Lane VM, Friend A, VanHooser K, et al. (2007) Sensitivity and specificity of culture and PCR of smegma samples of bulls experimentally infected with Tritrichomonas foetus. Theriogenology. 68: 853-860.

8. Schönmann MJ, BonDurant RH, Gardner IA, Van Hoosear K, Baltzer W, et al. (1994) Comparison of sampling and culture methods for the diagnosis of Tritrichomonas foetus infection in bulls. Vet Rec. 134: 620-622.

9. Parker S, Campbell J, Gajadhar A (2003) Comparison of the diagnostic sensitivity of a commercially available culture kit and a diagnostic culture test using Diamond's media for diagnosing Tritrichomonas foetus in bulls. J Vet Diagn Invest. 15: 460-465.

10. McMillen L, Lew AE (2006) Improved detection of Tritrichomonas foetus in bovine diagnostic specimens using a novel probe-based real time PCR assay. Vet Parasitol. 141: 204-215.

11. Garcia Guerra A, Hill JE, Campbell J, Waldner CL, Hendrick SH (2014) Use of pooled protozoal cultures of preputial scraping samples obtained from bulls for the detection of Tritrichomonas foetus by means of a realtime polymerase chain reaction assay. J Am Vet Med Assoc. 244: 352-356.

12. Kennedy JA, Pearl D, Tomky L, Carman J (2008) Pooled polymerase chain reaction to detect Tritrichomonas foetus in beef bulls. J Vet Diagn Invest. 20: 97-99. 